\title{
CLINICAL, BACTERIOLOGICAL AND HISTOPATHOLOGICAL PROFILE OF CHILDHOOD LEPROSY
}

\author{
Nivedita Devi Vukkadala1, Jukunta Chinni Krishna Lakshmana Pratap Kishore², Vasudha Varada ${ }^{3}$
}

${ }_{1}^{1}$ Professor and HOD, Department of DVL, Rangaraya Medical College, Kakinada.

${ }^{2}$ Assistant Professor, Department of DVL, Rangaraya Medical College, Kakinada.

${ }^{3}$ Final Year Student, Department of DVL, Rangaraya Medical College, Kakinada.

\section{ABSTRACT}

\section{BACKGROUND}

Leprosy is a chronic infectious disease caused by Mycobacterium leprae. A high proportion of childhood cases signifies active and recent transmission of the disease, making it a robust epidemiological indicator to assess the functioning of leprosy control programmes.

The objective of this study is to examine the clinical, bacteriological and histopathological characteristics of new childhood leprosy cases in GGH, Kakinada during a period of two and a half years from July 2014 to January 2016.

\section{MATERIALS AND METHODS}

Detailed history was taken. Examination of the skin and nerves was done. Slit Skin Smears [SSS] were done in all cases. Skin biopsies were done only in doubtful cases.

\section{RESULTS}

Of total 41 cases about 22 [53.65\%] were females and 19 [46.35\%] were males. Majority 30 [73.17\%] were of age group $10-15$, school going with low socio-economic background. Youngest child among them was 5 years old. Patch was the commonest presentation and extremities were the most common sites involved. Single patch was observed in 19 cases [46.34\%]. Most of the children were PB type 30 (73.17\%). Majority belonged to tuberculoid spectrum; 41.46\% - TT, 41.46\% - BT and 17.07\% Indeterminate type. One case of clinical BT case showed BL features histopathologically. SSS positivity was seen in 2 cases [4.8\%]; 10 [24.39\%] children had positive contact history; 8 cases [19.51\%] had thickened nerves, commonest being ulnar nerve followed by lateral popliteal nerve. One female child was HIV positive, who expired due to Pulmonary TB after completing treatment for leprosy.

\section{CONCLUSION}

School surveys are needed for early detection of cases and prevention of disabilities. Contact surveys help in detecting early disease, especially when there are children in the household. Leprosy control programmes should be designed to motivate the community for self-examination and reporting. Training of paramedical workers and health promotion are to be enhanced.

\section{KEYWORDS}

Child Leprosy, Active Transmission of Leprosy, Presentation of Leprosy in Children, Measures to Decrease Child Leprosy.

HOW TO CITE THIS ARTICLE: Vukkadala ND, Kishore JCKLP, Varada V. Clinical, bacteriological and histopathological profile of childhood leprosy. J. Evolution Med. Dent. Sci. 2017;6(24):2042-2045, DOI: 10.14260/Jemds/2017/445

\section{BACKGROUND}

Leprosy has been a major public health problem in many developing countries for centuries. Children are believed to be the most vulnerable group to Mycobacterium leprae given their nascent immunity and possible intrafamilial contact. ${ }^{1}$ According to the National Leprosy Elimination Programme (NLEP) report of March 2012 there were a total of about 0.13 million cases of leprosy in India, $9.7 \%$ of which were children. ${ }^{2}$ India leads the list of countries reporting high figures of leprosy globally with 1,34,752 new cases detected as on 31st of March 2013. ${ }^{3}$ In East Godavari district of Andhra Pradesh, the overall prevalence rate for the year 2014 - 2015 was $0.43 / 10000$ population and the proportion of child cases among new cases of leprosy for the year 2014 - 2015 was 16.3.

Financial or Other, Competing Interest: None.

Submission 15-02-2017, Peer Review 12-03-2017,

Acceptance 18-03-2017, Published 23-03-2017.

Corresponding Author:

Vasudha Varada

W/o. G. V. N. Pradeep,

\#9-11-139, Varun Heights,

B4, Gandhi Nagar, Kakinada-533001.

E-mail: vasudhavarada@gmail.com

DOI: $10.14260 /$ jemds $/ 2017 / 445$

\section{(c) (i) $\$$}

Although, there is a decline in the prevalence and new case detection rate in the recent years, the curve of children acquiring leprosy remains unturned accounting for more than $10 \%$ of the total new case load. ${ }^{3}$ The profile and magnitude of leprosy in paediatric populations have an important bearing on the epidemiology of the disease and reflect the level of control in a community. ${ }^{4}$ Besides, the prevalence of leprosy among children suggests possible lacunae in the operation of the national programmes aimed at elimination of leprosy from the society. ${ }^{5}$ A high child proportion signifies active and recent transmission of the disease, making it a robust epidemiological indicator to assess the progress of leprosy control programmes. ${ }^{4}$ With this setting, the present study aims at describing the epidemiological and clinico-pathological pattern of the disease occurring in the paediatric population in order to help strengthen control activities in the "post elimination era."

\footnotetext{
Aims and Objectives

To examine the clinical, bacteriological and histopathological characteristics of new childhood leprosy cases attending Government General Hospital, Kakinada during a period of two and a half years from July 2014 - January 2016.
} 


\section{MATERIALS AND METHODS}

A total of 41 patients were recorded during the study period. Detailed history regarding age, sex, site and number of skin lesions, presence of contact [intrafamilial and extrafamilial] was taken and examination of the skin and nerves (thickness and tenderness) was done. Clinical classification was made accordingly. Slit Skin Smears [SSS] examination was done in all cases. Slit Skin Smear (SSS) examination was performed using sterile scalpel blades using the standard techniques. The air-dried and heat-fixed smear was stained by ZiehlNeelsen carbol fuchsin stain and graded as per Ridley's scale for Bacteriological Index (BI). Skin biopsies were done only in doubtful cases (and with high index of clinical suspicion). A skin lesional biopsy was obtained using local anaesthesia following verbal consent from the patient (minor) and written informed consent from the guardian.

\section{RESULTS}

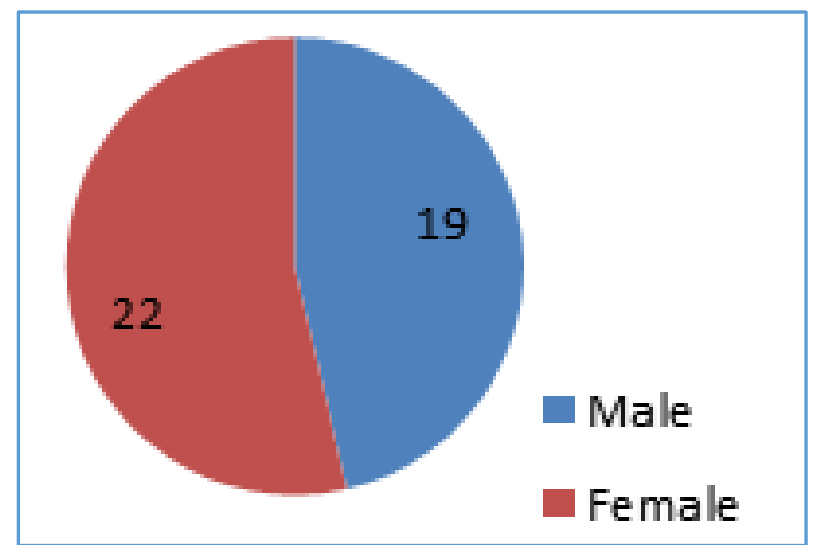

Sex Distribution- Out of 41 Children, 22 Children [53.65\%] were Female and 19 [46.35\%] were Male

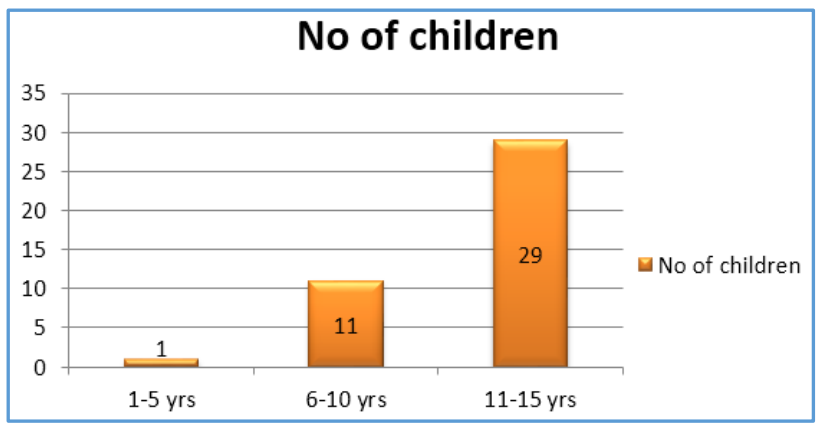

Age Distribution-Majority of the Children belonged to 1115 Years' Age Group. Only One Child is Present in 1- 5 Years' Age Group

Majority of the cases, 30 [73.17\%] belonged to PauciBacillary [PB] type and 11 [26.83\%] cases to Multi-Bacillary [MB] type.

\begin{tabular}{|c|c|c|}
\hline Type of Leprosy & Number & Percentage \\
\hline PB & 30 & $73.17 \%$ \\
\hline MB & 11 & $26.83 \%$ \\
\hline Total & $\mathbf{4 1}$ & $\mathbf{1 0 0 \%}$ \\
\hline \multicolumn{3}{|c|}{ Table 1 } \\
\hline
\end{tabular}

Patch was the common presentation. Extremities were the most common sites involved; 19 cases presented with single patch, out of which 4 cases had single facial patch.
8 cases [19.51\%] showed enlarged nerves, commonest being ulnar nerve followed by lateral popliteal nerve. Enlargement of greater auricular nerve was seen in one case. Type I reaction with facial nerve involvement was seen in another case. No deformity was detected in any of the cases in the present study. In the present study, majority of the cases belonged to tuberculoid spectrum of Ridley-Jopling [RJ] classification and the remaining cases belonged to Indeterminate Leprosy [IL]; 17 cases [41.46\%] belonged to TT type, 17 cases [41.46\%] belonged to BT type; 7 cases [17.07\%] belonged to IL type. No case of mid Borderline [BB] and Lepromatous spectrum [BL and LL] was seen.

Among 19 biopsies done, clinically diagnosed tuberculoid cases were 9 . Among 9 clinical TT cases, only 1 case showed histopathological correlation. In the remaining 8 TT cases, 4 cases (50\%) were BT histopathologically. The other half showed the features of superficial perivascular lymphocytic infiltrate. Among 8 clinically BT cases which were biopsied, 4 cases (50\%) showed clinico-histopathological correlation; 1 case was reported as TT, 1 was reported as IL and 1 case showed features of superficial perivascular lymphocytic infiltrate.

One case of BT was reported as BL type. This finding highlights the importance of histopathological evaluation during the management of leprosy cases. Among 2 cases of IL, only showed clinico-histopathological correlation.

\begin{tabular}{|c|c|c|c|c|c|c|c|c|c|}
\hline & & \multicolumn{7}{|c|}{ Histopathological Diagnosis } \\
\hline $\begin{array}{c}\text { Clinical } \\
\text { Type }\end{array}$ & No & TT & BT & BB & BL & LL & IL & HH & SPI \\
\hline TT & 9 & 1 & 4 & & & & & & 4 \\
\hline BT & 8 & 1 & 4 & & 1 & & 1 & & 1 \\
\hline IL & 2 & & & & & & 1 & & 1 \\
\hline Total & $\mathbf{1 9}$ & $\mathbf{2}$ & $\mathbf{8}$ & & $\mathbf{1}$ & & $\mathbf{2}$ & & $\mathbf{6}$ \\
\hline \multicolumn{10}{|c|}{ Table 2} \\
\hline
\end{tabular}

Slit Skin Smear (SSS) positivity of $1+$ was seen in 2 (4.8\%) cases out of 41 cases. The 2 cases were BT type. Remaining cases revealed SSS result as negative.

\begin{tabular}{|c|c|c|c|}
\hline Clinical Type & Number & Positive & Negative \\
\hline TT & 17 & 0 & 0 \\
\hline BT & 17 & 2 & 15 \\
\hline IL & 7 & 0 & 0 \\
\hline \multicolumn{4}{|c|}{ Table 3 } \\
\hline
\end{tabular}

In the present study, 10 [24.39\%] children had positive contact history.

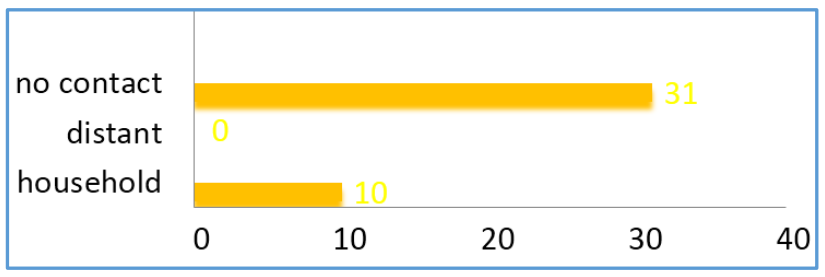

Among the children with positive history of contact, all the contacts were Multibacillary type except for one case where the contact was paucibacillary type. All the contacts completed 12 months course of treatment except for one who did not take treatment. All the contacts were fathers, except for one case where the contact was mother. One female child was HIV positive whose parents died of AIDS and the child 
expired due to pulmonary TB after completion of the course of MB-MDT for leprosy.

\section{DISCUSSION}

Leprosy continues to be a communicable disease of concern in the post-elimination era. Majority of the children in the present study were female. This is in contrast to a study done by Sachdeva et al. ${ }^{6}$ Largest age group observed was 11 - 15 years. This may be due to relatively long incubation period of leprosy. This is similar to a study by Ramesh Marne Bhat et $\mathrm{al},{ }^{3}$ where the majority (75\%) belonged to the age group of $11-14$ years followed by $19.44 \%$ and $5.56 \%$ in the $6-10$ years and $0-5$ years' age group. Paucibacillary cases were more in the present study. Similarly, in a study done by Sunil et al in Central India7 the proportion of paucibacillary cases were more as compared to multibacillary disease in children.

Patch was common clinical presentation in the present study. Similarly, in a study by Mahim Jain et al ${ }^{8}$ out of 24 cases studied, 11 cases presented with single patch. Ulnar nerve was common nerve involved in the present study. Similarly, in a study by A. G. Rao et $\mathrm{al}^{9}{ }^{9}$ the common nerve trunk involved was ulnar nerve followed by lateral popliteal nerve. Tuberculoid spectrum was common followed by indeterminate type in the present study. In a study done by Anand $\mathrm{J}$ et al in Government Medical College, Akola, Maharashtra. ${ }^{10}$ Out of 86 child leprosy cases, Borderline tuberculoid leprosy (77\%) was the commonest type followed by Tuberculoid leprosy (7\%), Borderline (6\%), Indeterminate leprosy (3.5\%), Pure neuritic (2.3\%) and Borderline Lepromatous (5\%). SSS positivity was seen in 2 cases $(4.8 \%)$ in our study. In a study by Singal A et al done in Delhi, ${ }^{11}$ slit skin smears were positive in 34 (19.8\%) patients out of 172 cases of child leprosy in a ten-year period study; 10 (24.39\%) patients revealed positive contact history in the present study. In a study by Selvesekar A et al,12 nearly $30 \%$ of 794 new childhood leprosy cases during a six-year study had history of household contacts with leprosy, mostly parents or grandparents. There is an observation of increased level of intrafamilial contacts with leprosy in the cases of our study, strengthening the strategy of screening children in leprosyaffected households and necessary health education regarding preventive measures.

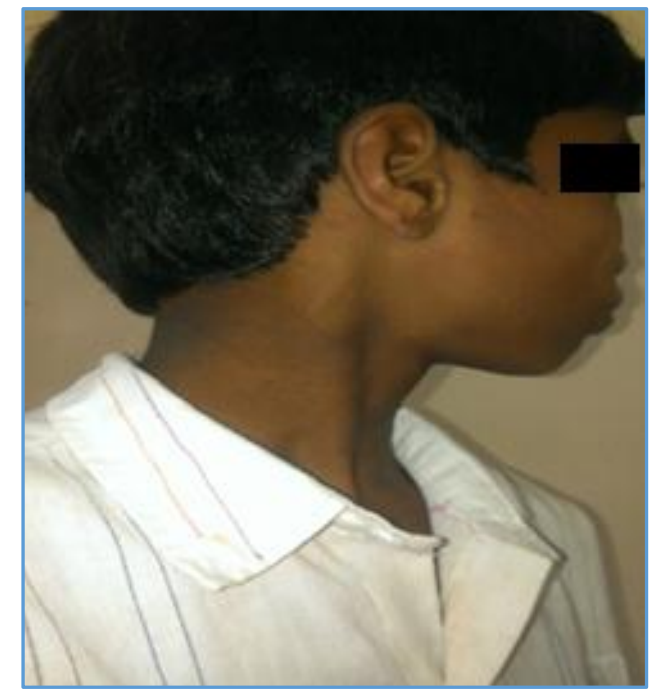

TT Patch

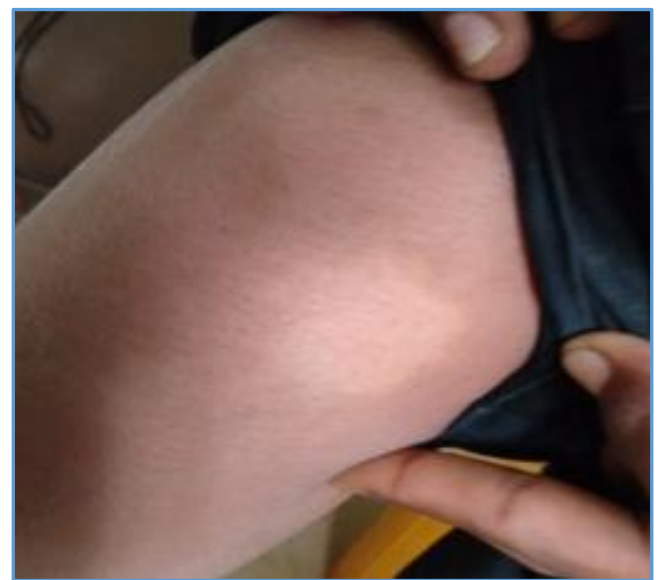

Enlargement of Greater Auricular Nerve

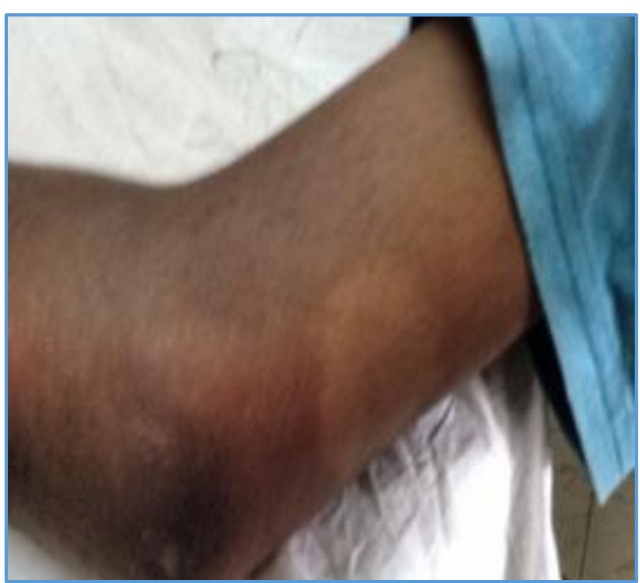

BT Patch

\section{CONCLUSION}

Our study and reports from different parts of the country depict the unturned curves in the epidemiology of childhood leprosy in its endemic pockets, which mirrors active transmission and delayed diagnosis in this age group. This indicates the need to strengthen contact screening, early case detection, referral and followup for adherence and treatment in the paediatric population to sustain elimination and prevent the development of severe devastating or crippling adult form of the disease. For MB cases, MDT therapy should be continued beyond 1 year in the presence of active disease, because incomplete and inadequate treatment may lead to resistance of the organism and reactions and more and more MB cases. Since there is a significant finding of contact history in our study, we suggest promotion of active surveillance to identify the undetected hidden leprosy cases by conducting screening camps in schools and orphanages and educating them and distributing free medicines. Enhancement of living standards of the poor may help in decreasing the disease burden. Indian Association of Dermatologists, Venereologists and Leprologists (IADVL) adopted the theme "Wake up, Feel the Pain, Prevent stigma" for this year's Leprosy Day on 30-12017. The still high prevalence of childhood leprosy in our area gives a wakeup call to the Government for modification of existing strategies in order to achieve real success of the National Leprosy Elimination Programme. 


\section{REFERENCES}

[1] Singal A, Chhabra N. Childhood leprosy. In: Kumar B, Kar HK, eds. IAL textbook of leprosy. $2^{\text {nd }}$ edn. New Delhi: Jaypee Publishers 2016: p. 360.

[2] Shetty VP, Ghate SD, Wakade AV, et al. Clinical, bacteriological, and histopathological characteristics of newly detected children with leprosy: a population based study in a defined rural and urban area of Maharashtra, western India. Indian J Dermatol Venereol Leprol 2013;79(4):512-7.

[3] Chaitra P, Bhat RM. Postelimination status of childhood leprosy: report from a tertiary-care hospital in south India. Biomed Res Int 2013;2013:328673.

[4] Atukorala DN. Leprosy and the child in Sri Lanka. Sri Lanka Journal of Child Health 2003;32(4):89-91.

[5] Das L, Meher BK, Das NB, et al. A clinco-bacteriological study of leprosy in paediatric age group. Advancements in Infectious Diseases 2013;3(4):26973.

[6] Sandeep S, Amin SS, Alam ZKS, et al. Childhood leprosy: a retrospective study. Journal of Public Health and Epidemiology 2010;2(9):267-71.
[7] Gitte SV, Sabat RN, Kamble KM. Childhood leprosy in an endemic area of central India. Indian Pediatr 2016;53(3):221-4.

[8] Jain M, Nayak CS, Chokkar R, et al. Clinical, bacteriological, and histopathological characteristics of children with leprosy: a retrospective, analytical study in dermatology outpatient department of tertiary care centre. Indian Journal of Paediatric Dermatology 2014;15(1):16-9.

[9] Rao AG. Study of leprosy in children. Indian J Lepr 2009;81(4):195-7.

[10] Anand AJ. Profile of disability in children with leprosy. International Journal of Scientific and Research Publications 2015;5(10):1-4.

[11] Singal AS, Sonthalia, Pandhi D. Childhood leprosy in a tertiary-care hospital in Delhi, India: a reappraisal in the post elimination era. Lepr Rev 2011;82(3):259-69.

[12] Selvasekar A, Geetha J, Nisha K, et al. Childhood leprosy in an endemic area. Lepr Rev 1999;70(1):21-7. 